\title{
Não há outra igual
}

\section{There is no other like it}

\author{
Francisco Verardi Bocca ${ }^{1}$ \\ Professor Titular do Programa de Pós-Graduação em Filosofia da PUCPR \\ E-mail : franscisco.bocca@pucpr.br
}

Resumo: o presente artigo atende ao escopo de realizar uma homenagem justa ao filósofo Zeljko Loparic, tendo como meio relatar a influência que ele exerceu sobre meu próprio trabalho de reflexão sobre a psicanálise de Freud. Esta se deu pela adoção da noção de paradigma, que Loparic tomou de empréstimo de Thomas Kuhn ("A estrutura das revoluções científicas", 1962). O resultado disso foi que pude reconhecer diferentes psicanálises pós-freudianas dando nome próprio para cada uma, mas especialmente reconhecendo a obra de Freud como não havendo outra que lhe seja igual. Em outras palavras, me permitiu apurar minha compreensão acerca da condição especial e de sua distinção. Não tenho dúvidas de que se trata de uma reflexão pertinente em épocas em que o uso compartilhado de teorias e terapias psicanalíticas tem sido tão festejado.

Palavras-chave: Homenagem; Psicanálise; Freud; Kuhn; Paradigma.

\begin{abstract}
Zeljko Loparic by reporting his influence on my own work of reflection on Freud's psychoanalysis. It was due to the adoption of the notion of paradigm, which Loparic borrowed from Thomas Kuhn ("The Structure of Scientific Revolutions", 1962). As a result, I was able to recognize different post-Freudian psychoanalysis giving a proper name to each one, but especially recognizing that there is no other work like Freud's. In other words, it allowed me to improve my understanding of the special condition and its distinction. I

\footnotetext{
${ }^{1}$ Francisco Verardi Bocca é graduado em Arquitetura e Urbanismo pela PUCCAMP (1985); bacharel e licenciado em Filosofia pela UNICAMP (1997); mestre em Filosofia pela UNICAMP (1994) e doutor em Filosofia pela UNICAMP (2001). Pós-doutor em Filosofia pela UFSCar (2009) e pela Universidade de Paris VII - Denis Diderot (2014). Professor Titular do Curso de Filosofia e do Programa de Mestrado e Doutorado em Filosofia da Pontifícia Universidade Católica do Paraná. Atua nos seguintes temas: filosofia da história, psicanálise, literatura e ética. Compõe e coordena a linha de pesquisa Filosofia da Psicanálise, Compõe e lidera o grupo de pesquisa Filosofia da Psicanálise (PUCPR) cadastrado no CNPQ. Compõe ainda os grupos de pesquisa Filosofia e Psicanálise (UFSCar) e Filosofia e Práticas Psicoterápicas (UNICAMP) cadastrados no CNPQ. No biênio de 2008 a 2009 ocupou a coordenação do G. T. Filosofia e Psicanálise da ANPOF. Membro associado da Associação Brasileira de Estudos do Século XVIII. Foi bolsista produtividade pela Fundação Araucária - PR no ano de 2013. É co-autor da obra "Ontologia sem espelhos" (Ed. CRV, 2015) (Reeditada em 2019 pela editora L`Harmattan, Paris) e autor da obra "Do Estado à Orgia" (Ed. CRV, 2016).
} 
have no doubt that this is a pertinent reflection at times when the shared use of psychoanalytic theories and therapies has been so celebrated.

Keywords: Tribute; Psychoanalysis; Freud; Kuhn; Paradigm.

Ter sido aluno de Zeljko Loparic nos cursos de Graduação e de Pós-graduação da Unicamp nos anos 1990 foi uma grande experiência. Tê-lo assistido, mais tarde, em congressos da área foi ainda melhor. Mas ter tido o privilégio de compartilhar, na condição de colega, desde 2011, um seminário no Programa de Pós-Graduação em Filosofia da Pontifícia Universidade Católica do Paraná foi o máximo. Seminário tradicional e prestigiado por muitos alunos e colegas que por lá passaram. Nele, a tolerância e o pluralismo de ideias sempre foram compromissos e o debate se dava, acreditem, de maneira desinteressada e generosa. Nesse período, só não entramos em acordo em relação à Sade, o que deu mais consistência às minhas convicções e nos divertiu enormemente.

Trabalhar com Loparic foi compartilhar, em primeiro lugar, de sua erudição, mas também de seu brilho pessoal. Das reflexões que compartilhamos sobre autores, obras e conceitos, reservei uma para comentar neste texto. Especialmente pelo efeito que provocou em meu próprio trabalho, quero dizer, em minha própria reflexão sobre a psicanálise de Freud, à qual me dedico. Trata-se da noção de paradigma, que Loparic tomou de empréstimo de Thomas Kuhn, em "A estrutura das revoluções científicas”, de 1962. Disseminou-a entre nós aplicando-a com muita propriedade à psicanálise em geral. O resultado disso foi que aprendemos a chamá-las psicanálises ou a dar nome próprio para cada uma.

Várias foram suas publicações sobre essa noção. Relembro algumas: "O paradigma winnicottiano e o futuro da psicanálise" (Revista Brasileira de Psicanálise, v. 42, 2008); "De Freud a Winnicott: aspectos de uma mudança paradigmática" (Revista Natureza Humana, v. 8, 2006); "Um novo paradigma" (Revista Viver Mente \& Cérebro Especial, v. 5, 2005); “Winnicott's Paradigm Outlined" (Revista Latinoamericana de Psicopatologia Fundamental, v. 5, 2002); "Esboço do paradigma winnicottiano" (Cadernos de História e Filosofia da Ciência, v. 11, 2001); e "Resistências à psicanálise" (Cadernos de História e Filosofia da Ciência, n. 8, 1985).

Como disse acima, o fato é que ele me permitiu apurar minha própria compreensão acerca da obra de Freud e de sua condição especial, quero dizer, de sua 
distinção. Permitiu-me pensá-la, como fizeram Kuhn e Loparic, sob a perspectiva da história, de sua história, de seu desenvolvimento, vale dizer, sob a perspectiva do "progresso" científico. Não tenho dúvidas de que se trata de uma reflexão pertinente em épocas em que o uso compartilhado de teorias e terapias tem sido tão festejado ${ }^{2}$.

De início, quero esclarecer que utilizo aqui o termo paradigma no estrito sentido de Kuhn e nem mesmo no de Loparic. Na verdade, me considero entre aqueles que o utilizam como sinônimo de modelo, ou seja, em um sentido mais restrito e de cunho popular. Sobre isso, o próprio Kuhn admitiu a equivalência ao declarar que "No seu uso estabelecido, um paradigma é um modelo ou padrão aceitos" (1998, p. 43), voltando atrás em seguida: "Mas dentro em pouco ficará claro que o sentido de 'modelo' ou 'padrão' não é o mesmo que o habitualmente empregado na definição de 'paradigma"” (1998, p. 43). O fato é que estou consciente da imprecisão e do risco de inadequação. De fato, não estou nem mesmo certo se a psicanálise comporta o uso desse conceito, uma vez que foi criado para as ciências naturais. Nem mesmo estou certo se a psicanálise de Freud estaria madura a ponto de ter constituído um paradigma (o próprio Kuhn não a considerava uma teoria científica, mas uma prática) e que, por si só, seria capaz de viabilizar a chamada pesquisa normal, solucionadora de quebra-cabeças.

O uso do conceito me exigiu fazer vista grossa quanto ao fato de que uma ciência se torna um paradigma quando se constrói no interior de uma comunidade científica que compartilha crenças e valores ${ }^{3}$. Isso só valeria para a psicanálise caso consideremos como tal o grupo das quartas-feiras coordenado por Freud nas dependências de seu consultório; sem esquecer que alguns de seus participantes foram criadores de outras escolas psicanalíticas, produzindo modificações teóricas relevantes e divergentes.

Mas foi com denodo e convicção, além de engenhosidade, que Loparic (2006), inspirado em Kuhn, definiu a psicanálise de Freud como composta por exemplares (complexo de Édipo), generalizações simbólicas (generalizações-guia: teoria da

\footnotetext{
2 Sobre isso, ver meu capítulo "Contribuição para o debate acerca de 'uso compartilhado' em psicanálise", 2016.

${ }^{3}$ Se bem que no posfácio de 1969 , Kuhn se propôs (p. 219) justamente a "desligar", pelo menos da maneira como fez em 1962, o conceito de paradigma da noção de comunidade científica, ou seja, de que um paradigma é simplesmente aquilo que os membros de uma comunidade compartilham. Seria mais adequada, segundo ele, se essa comunidade científica fosse considerada sob o ponto de vista de uma estrutura comunitária da ciência, o que implica na noção particular de comunidade científica (p. 220) que, dificilmente, seria aplicada sem problemas no caso do grupo de Freud bem como de seus seguidores posteriores.
} 
sexualidade), modelos metafísicos (modelos heurísticos), valores (teóricos e práticos), predições, utilidade da ciência etc., os quais, no conjunto, dão configuração a uma unidade paradigmática tal como definido por Kuhn. A propósito, Loparic (2006) chamou o paradigma de Freud (no qual inclui Klein, Bion e Lacan) de psicanálise tradicional, ou ainda, de Édipo ou triangular. Já o de Winnicott, chamou-o não edípico, o bebê no colo da mãe.

Meu objetivo, bem mais modesto, ao considerar a obra de Freud, é mostrar o quanto, em seu desenvolvimento, este seguiu direções opostas a de seus próprios mestres. Se trata de, por meio da noção de paradigma, esclarecer e distinguir a visão de mundo que sua teoria sustenta. Assim, a noção de paradigma me ajudou a esclarecer uma certa generalização acerca da construção teórica de Freud, por exemplo, de que teria sido o resultado de uma grande interdisciplinaridade científica, forjada entre abundantes contribuições e influências científicas, filosóficas e artísticas que ele próprio recebeu, se apropriou e reelaborou. Mas a questão posta por Loparic é a de saber se o produto final freudiano apresenta ou não compatibilidade em relação tanto a seus mestres quanto às outras psicanálises que se seguiram. Em outras palavras, se é comensurável ou não em relação a elas.

Não custa lembrar que a obra de Freud (a qual, com razão, não deve ser considerada a obra de um só homem) constituiu um campo fecundo de proliferação de novas teorias, sem mesmo poder ser considerada uma ciência de contornos bem definidos, uma ciência normal. O fato é que o próprio movimento de fundação da psicanálise, que teve em Freud seu maior representante, nunca cessou de proliferar. A questão que não cala é a de saber até que ponto os diferentes resultados se mostraram conciliáveis ou se são de fato incompatíveis entre si. Em outros termos, se a psicanálise de Freud produziu frutos a partir de um movimento gradual, contínuo e acumulativo ou a partir de um movimento brusco e descontínuo que produziu paradigmas incomensuráveis com sua origem. Loparic já mostrou que de Freud à Winnicott não há trânsito ${ }^{4}$, mas uma revolução. Se levarmos Kuhn ao pé da letra, entre eles teria ocorrido uma mudança de concepção de mundo.

\footnotetext{
${ }^{4}$ Sobre isso, o próprio Kuhn reconheceu (1998, p. 190) que os novos paradigmas nascem dos antigos, que incorporam parte do vocabulário e dos aparatos conceituais e de manipulação de dados. No entanto, adverte que raramente utilizam esses elementos da mesma maneira, de modo que termos, conceitos e experiências antigas servem para estabelecer novas relações e sentidos entre si.
} 
Uma mudança, convenhamos, que não seria da ordem de um progresso em termos de acumulação de conhecimento. Até porque a própria noção de acumulação estaria assegurada, de acordo com Kuhn (1998, p. 205), “[...] somente durante aqueles períodos em que predomina a ciência normal”. Embora, como o próprio autor admite, todo aquele que troca de paradigma pode ou não considerar a mudança um progresso acumulativo, contanto que tenha o bom senso de não o considerar um tipo de aproximação maior em relação à verdade 5 . Deve, sim, considerar sua ciência como apenas um instrumento, mais eficaz certamente, para a resolução de quebra-cabeças.

Claro que não vou me ocupar aqui de Winnicott e de seu modelo relacional, posto já ter sido suficientemente tratado por Loparic. Se a teoria desenvolvida por Winnicott corresponde a uma revolução científica, há de ser irreconciliável manifestar incompatibilidade com a de Freud. Incompatibilidade e desacordo que, espero, não implique na expectativa de destruição do paradigma anterior e nem em um conflito entre escolas rivais, até porque, como reconheceu Kuhn, “[...] a competição entre paradigmas não é o tipo de batalha que possa ser resolvido por meio de provas" (1998, p. 189), mas de fé e persuasão. Para o autor, cada um “[...] precisa ter fé na capacidade do novo paradigma para resolver os grandes problemas com que se defronta, sabendo apenas que o paradigma anterior fracassou em alguns deles" (1998, p. 198).

Pois bem, para alcançar algum resultado minimamente satisfatório, primeiro adotei a estratégia de rememorar algumas influências teóricas que Freud recebeu em sua formação para comparar, em seguida, com suas próprias elaborações teóricas. Não se trata de um inventário exaustivo, mas de destacar a oposição entre a homeostase de seus mestres e a sua entropia na consideração, por exemplo, da fisiologia neural. Epistemologicamente, trata-se de considerar, na medida do possível, alguns conceitos de Freud em uma perspectiva histórica e de conjunto que permita compreendê-los em suas relações internas de produção e de sentido. Parafraseando Monzani (2014), compreender esses conceitos no interior do movimento do pensamento de Freud. Ponto de vista que, espero, permite o reconhecimento da identidade e da distinção do

\footnotetext{
${ }^{5}$ Sobre essa questão, Kuhn foi explícito ao afirmar que "O processo de desenvolvimento descrito neste ensaio é um processo de evolução a partir de um início primitivo - processo cujos estágios sucessivos caracterizam-se por uma compreensão sempre mais refinada e detalhada da natureza. Mas nada do que foi ou será dito transforma-o num processo de evolução em direção a algo" (1998, p. 213). A algo estabelecido de antemão pela natureza.
} 
pensamento de Freud ${ }^{6}$, bem como de sua incompatibilidade (para não abusar do termo incomensurabilidade) em relação aos seus pósteros.

$$
* * * * *
$$

Os biógrafos de Freud, assim como os historiadores da psicanálise, informam que, em sua formação acadêmica em medicina, estagiou por seis anos no Instituto de Fisiologia de Ernst Brücke, onde consolidou a prática de pesquisa científica anatômica. Pela aplicação das técnicas histológicas desenvolvidas e pela posterior troca do Instituto pelo hospital de Meynert e, mais tarde, pelo de Charcot, Freud ampliou em muito seu foco de interesse. Mas o fato curioso foi o contato inicial com uma fisiologia pautada no princípio termodinâmico da conservação de energia, solidário da tese de que mesmo um sistema isolado pode sustentar de maneira constante uma determinada soma de energia. Trata-se de uma tese que foi atualizada por R. Mayer em 1842 acompanhada da postulação de um princípio energético único. Ela inaugurou um ambiente científico que se estendeu a Helmholtz e, antes dele, a Herbart.

Pode-se dizer que Freud participou desse processo de construção de uma psicologia científica com acento dinâmico e econômico, segundo consideração das representações enquanto fatos psicológicos, mas sob a condição de conflito representacional de uma mecânica de representações. Dessa forma, estas ganharam o status de unidade de base do fenômeno psíquico e, por isso, tornaram-se objeto de investigação. Foi estabelecida uma unidade compreensível em termos de representação e força, mensurável, quantificável, plenamente de acordo com as exigências da psicologia científica do século XIX, cujo representante notável foi Wundt em seu laboratório de psicologia em Leipzig. Tratava-se de uma disciplina com pretensões de ciência natural, pretensões as quais Freud compartilhou plenamente.

Tudo isso implicava admitir que a oposição entre as representações se manifestava como força, impulso e movimento, tanto de afastamento quanto de aproximação, de associação. Significava também que o psiquismo não seria outra coisa

\footnotetext{
${ }^{6}$ Uma identidade que poderia ser indicada recorrendo ao conceito de autoctonia de Lebrun (L'idée d'épistémologie, de 1977, que recebeu inspiração de Kuhn). Para o autor, uma ciência constrói sua própria racionalidade e é, por isso, regional e sobretudo autóctone. Nesse caso, a obra de Freud seria considerada como um texto e seu interesse maior recairia sobre o esclarecimento de sua ordem interna, mas não em detrimento de suas fronteiras com outras ciências, outros textos.
} 
senão um composto de cadeias de representações em conflito equipado com um Eu agenciador. Como todos sabem, trata-se de uma concepção representacional-fisicalista do psiquismo que Freud sustentou até certo ponto. Não endossou, por exemplo, a tese de Herbart de que "por detrás dessa tese psicológica, oculta-se uma tese metafísica. A alma é representada como uma substância simples que tende a autoconservar-se: cada representação constitui um ato particular pelo qual a alma se conserva" (Assoun, 1983, p. 151).

No campo das afinidades, sublinho o uso e a importância dada ao conceito de força ${ }^{7}$. Como Fechner, Freud tomou clara opção pelo monismo de Haeckel. Aliado à concepção "quantitativista" do psiquismo, estabeleceram uma relação direta entre excitações e sensações, entre um dado físico e outro psíquico, sustentando uma psicofísica às voltas com a exigência de medição dos fenômenos psíquicos, particularmente de seus deslocamentos quantitativos organizados segundo uma tendência primordial à estabilidade.

Mas foi por meio de Helmholtz que o princípio de estabilidade e conservação de energia ganhou reforço e aplicação aos fatos fisiológicos, articulando de vez a neurologia à psicologia, possibilitando em definitivo uma psicofisiologia. Nessa perspectiva, a força é caracterizada pela variabilidade e indestrutibilidade, ou seja, se transforma sem se anular, sem se desgastar; pode-se dizer, homeostaticamente, segundo um mecanismo de regulação que visa conservar constantes as condições da vida, para o que mobiliza os mais diversos sistemas, como o nervoso.

Dito isso, concluo que Freud foi um infiel discípulo de seus mestres, pois, em sua psicologia profunda, levou em consideração fenômenos representacionais organizados segundo processos orientados por princípios entrópicos a partir de uma concepção de força/energia que implica uma transformação aos modos de um gasto, de um escoamento que visa o repouso. Dessa forma, sua psicanálise consistiu desde o começo em um instrumento teórico singular que comportava uma visão de mundo descontínua de suas influências.

Para avançar no esclarecimento da incompatibilidade que alego, organizei as páginas seguintes em dois tópicos. Desconsiderando a ordem cronológica, no primeiro, privilégio o artigo de 1911 intitulado "Formulações sobre os dois princípios de

\footnotetext{
7 Sobre o sentido heurístico que Freud lhe atribuiu, ver meu artigo Freud e o programa científico kantiano. Revista Natureza Humana, v. 18, n. 2, 2017.
} 
funcionamento mental" (doravante "Formulações"), destacando o dispositivo do teste de realidade e a relação problemática do aparelho psíquico com a realidade. No segundo, articulando o artigo de 1895, intitulado "Projeto de uma psicologia" (doravante "Projeto") com "Além do princípio do prazer" (doravante “Além do princípio"), de 1920, destaco o estatuto da noção de prazer e de sua negatividade. De ambos, espero que permitam justificar a finalidade entrópica que, segundo entendo, Freud atribuiu ao homem e, por extensão, à civilização. Tudo para, por fim, indicar com alguma consistência certos aspectos específicos de seu pensamento que o tornaram irredutível a seus antecessores e pósteros.

Pois bem, no artigo Formulações, no qual Freud se ocupou fundamentalmente da tarefa de expor a distinção entre os dois princípios reguladores do funcionamento mental, como revela seu título, expôs também os dois processos, o primário e o secundário sob seus domínios. Distinções que subsidiaram sua investigação acerca da gênese do que chamou aparelho psíquico, decorrente de sua relação com os estímulos endógenos e os provenientes da realidade exterior. Entre seus achados de grande relevância encontra-se o de que "[...] os neuróticos afastam-se da realidade por achá-la insuportável - seja no todo ou em parte" (1911, p. 237); uma contrariedade decorrente da incapacidade inicial do aparelho psíquico de distinguir uma alucinação de uma percepção real. Por conta disso, esclareceu que o propósito de seu artigo era o de "trazer a significação psicológica do mundo externo e real para a estrutura de nossas teorias" (1911, p. 237).

Essa obra proporcionou, quanto ao teste de realidade, uma oportunidade de investigar o que Porchat chamou de "o momento de seu estabelecimento" (2005, p. 35), uma ocasião fundamental para compreender seu funcionamento e sua aplicação ao longo da vida. A distinção entre os dois momentos (o de estabelecimento e o de aplicação) foi importante para revelar a natureza e as consequências do teste de realidade. O primeiro deles levou em conta o aparelho psíquico em seu estágio mais primitivo e elementar, enquanto o segundo, sua aplicação na vida adulta e complexa. Destaco que, no primeiro momento, o que caracteriza o pequeno infante seria, segundo Freud, sua condição inerme, indefesa, o que demandaria um ou vários dispositivos de 
proteção contra estímulos internos e externos, aparentemente visando sua conservação, mas também sua imobilidade e quietude. Tudo pode ser mais bem compreendido ao considerarmos o arco-reflexo como seu modo de operação.

Como diz Porchat, trata-se de "[...] um aparelho que tende à alucinação e não ao reconhecimento da realidade externa" (2005, p. 43) e que, por isso mesmo, “[...] fornece o significado inicial do conceito de teste de realidade" (2005, p. 43). Tudo indica que o procedimento alucinatório seria um paliativo em termos de defesa contra estímulos, operante quando da impossibilidade de aplicação imediata do arco-reflexo. Este, sim, possibilitador do escoamento total de estímulos, proporcionando a quietude visada. $\mathrm{O}$ raciocínio é simples: se a demanda persiste, alucina-se sua realização. O fato é que também essa providência estaria condenada ao fracasso, o que impulsionaria o aparelho psíquico a perseguir dois objetivos. Em primeiro lugar, o de impedir a satisfação, ainda que parcial, pela via da alucinação. Em segundo, o de possibilitar ao Eu o encontro de objetos de satisfação no mundo exterior; para isso, é necessário conhecê-lo. Tratemos, portanto, de ambos.

A alucinação se justifica em razão de um ponto de partida admitido por Freud, a presença de processos inconscientes, reconhecidos como os mais antigos na ordem do desenvolvimento psíquico, próprios de uma fase de desenvolvimento onde atuavam com exclusividade. Acrescentou que tais processos eram desde sempre regidos por um princípio, o “[...] princípio de prazer-desprazer, ou simplesmente, princípio de prazer" (1911, p. 238). Concebeu-o como o reitor do desenvolvimento do aparelho psíquico, embora talvez não de maneira exclusiva. Reservo as considerações das implicações desse princípio para mais tarde.

Como bom materialista-evolucionista, Freud insistiu no fato de que as exigências das necessidades internas, além das externas, disparam e impulsionam a produção da maquinaria psíquica. Nesses termos, seria diante da ocorrência dos estímulos internos que "[...] tudo que havia sido pensado (desejado) foi simplesmente apresentado de maneira alucinatória, tal como ainda acontece com nossos pensamentos oníricos a cada noite" (Freud, 1911, p. 238). Como se vê, o próprio ato de alucinar foi compreendido como uma tentativa primitiva e imperfeita de realização do propósito do aparelho psíquico.

Isso porque essa providência seria expressão do processo primário que permite apenas “[...] afastar-se de qualquer evento que possa despertar desprazer (aqui temos a 
repressão)" (Freud, 1911, p. 238), atendendo precariamente à “[...] tendência a afastarse de impressões aflitivas" (Freud, 1911, p. 238), esclareceu Freud. No entanto, justamente a partir desse fracasso teria emergido o sistema de memória, fundamental para a aplicação do teste de realidade. Curiosamente, o mesmo sistema que possibilita a orientação de uma ação motora adequada na medida em que oferece registros de caminhos preferenciais para a descarga de estímulos é também o que oportuniza a alucinação, portanto, não seria a memória por si só o elemento decisivo para a distinção entre as fontes de estimulação.

O fato é que o recurso à alucinação acaba de alguma forma inibido, torna-se obsoleto pelo desapontamento, pela ausência da satisfação esperada e pela insistência do estímulo e, portanto, pela sobrevivência do desprazer. Diante de tudo isso, Freud identificou uma consequência dada em dois tempos. De início, o abandono da iniciativa alucinatória; em seguida a emergência de uma nova providência, tomada por parte de um Eu primitivo, mas já capacitado para a tarefa que consiste em "[...] decidir tomar uma concepção das circunstâncias reais no mundo externo e empenhar-se por efetuar nelas uma alteração real" (Freud, 1911, p. 238). Pode-se dizer que um novo princípio de funcionamento psíquico foi requerido, ao qual Freud chamou de princípio de realidade. O que se segue a partir disso seria a superação da condição inerme e ensimesmada do organismo vivo, criando, ao que parece, as condições iniciais de sua sobrevivência pela complexificação organizacional.

Isso porque, a partir da diferenciação das fontes dos estímulos, "o que se apresentava na mente não era mais o agradável, mas o real, mesmo que acontecesse ser desagradável” (Freud, 1911, p. 238). Freud atribuiu essa operação ao Eu que se dirige aos objetos exteriores e providencia seu retorno, na verdade, seu reencontro. Isso seria possível pelo recurso crescente dos órgãos sensoriais e da consciência a eles relacionada. Assim, o Eu passa a experimentar e reconhecer outras sensações, inclusive com o acréscimo de novas qualidades sensoriais além do prazer-desprazer, a partir das quais são possibilitadas comparações mais eficazes.

Como descrito por Freud, o Eu passa a operar contando com a maior "[...] importância dos órgãos sensoriais, que se acham dirigidos para esse mundo externo e da consciência a eles ligada” (1911, p. 239). Disto decorre a própria complexificação do aparelho psíquico por meio de mais uma e especial função: a atenção. Sobre ela, Freud 
disse que “[...] sua atividade vai encontrar as impressões sensórias a meio caminho, ao invés de esperar por seu aparecimento" (1911, p. 239).

Todo o processo que antecede a memória e a atenção foi assim resumido por Freud (1911, p. 238), “O bebê revela seu desprazer, quando há um aumento de estímulo e uma ausência de satisfação, pela descarga motora de gritar e debater-se com os braços e pernas, e então experimenta a satisfação que alucinou". Trata-se, assim, a princípio, de uma experiência de, pelo menos, duas etapas: uma motora, que parece absolutamente involuntária (fadada ao fracasso, já que o escoamento da tensão é breve), e outra alucinatória (igualmente fadada ao fracasso). Até aqui, como dito acima, tudo é movido pelo processo primário orientado pelo princípio do prazer.

Superada essa fase, o desenvolvimento das funções psíquicas sofisticadas, como a memória e a atenção, proporciona o que Freud chamou de julgamento imparcial. Julgamento decorrente de funções psíquicas que executam a tarefa de "[...] discernir se determinada idéia era verdadeira ou falsa, isto é, se se achava ou não em concordância com a realidade, decisão que era determinada efetuando-se uma comparação com os traços de memória da realidade" (Freud, 1911, p. 239). Até aqui, em harmonia com seus contemporâneos, a possibilidade de adaptação do homem à realidade e sua conservação como efeito dela estavam desenhadas.

No entanto, pergunto se essa sofisticação do aparelho psíquico como um todo corresponderia efetivamente a um processo adaptativo sustentável. Se sim, ela decorreria, de alguma forma, de algo como uma boa "regra biológica". Na ausência desta, teríamos que reconhecer que o arco-reflexo (também ele) sob a regência do Princípio do prazer seria incompatível e constituiria obstáculo à adaptação do homem à realidade; especialmente tratando-se de um organismo que, despossuído de qualquer tendência à integração, visa o retorno ao estado inorgânico que o precedeu (argumento que Freud finalmente formulou em 1920).

Experimentemos o argumento, sugerido por Freud, de que algo da ordem da adaptação e da conservação da vida decorreria, não de uma regra biológica atuando no bebê, mas de uma intervenção do exterior, da ação provedora familiar, além das mais diversas formas culturais. Com isso, o verdadeiro processo que promoveria o desenvolvimento do $\mathrm{Eu}$ e que resultaria em adaptação e sofisticação do aparelho psíquico, a introdução do Princípio de realidade, proveria dos interesses de agentes parentais. Este parece um bom argumento, pois desloca para o exterior a dificuldade de 
reconhecer no organismo vivo um processo de auto formação. Mas não tão bom se considerarmos que a ordem exterior, além de não suprimir o Princípio do prazer e seu interesse primordial, oferece, quando muito, motivos (ou oportunidades) para o aparelho psíquico estender a vida e suportar tensões segundo uma existência a contragosto.

O que quero dizer é que, nessas condições, a descarga motora não passa a ser anulada, mas possibilitada por meio de uma operação racional; por uma operação do Eu no controle da motricidade, promovendo uma ação que apenas se parece com uma conquista do Princípio do prazer pelo Princípio de realidade. No entanto, segundo o próprio argumento de Freud, “[...] a descarga motora foi empregada na alteração apropriada da realidade; foi transformada em ação" (1911, p. 240). Tudo isto segundo um processo superior do pensar que, por meio de articulação coerente de cadeias de representações, produz uma verdadeira transformação do ego-prazer em ego-realidade, que tolera tensões e promove escoamentos, ainda que parciais.

Isso é verdade, pois ocorre uma coexistência (nunca uma eliminação) do processo primário com o secundário; coexistência que confere ao aparelho psíquico um tipo de funcionamento o qual tolera uma carga mínima de tensão. Nesse caso, estaria operando mais um princípio, o Princípio de constância. Mas também é verdade que em lugar de pensarmos a constância como uma possibilidade subsistente, podemos pensá-la como estratégia de adiamento da descarga final da excitação por outros meios que o motor e a alucinação. Em lugar de catexias móveis de pronto escoamento, catexias vinculadas para escoamento postergado. Voltarei a essa questão adiante.

Vale lembrar que, nessa obra, Freud ainda tirou outra consequência da distinção entre Princípio do prazer e Princípio de realidade, assim como entre processos primários e secundários. Uma função psíquica que persiste após a introdução do Princípio de realidade: o fantasiar. Esta, como disse, "foi liberada no teste de realidade" (Freud, 1911, p. 240). Como sabemos, por esse argumento explicou os fundamentos das atividades artísticas, dos jogos infantis, entre outras coisas que o teste não impede de ocorrer, como ainda o sonho, o estado hipnótico, a paixão, a identificação com o líder etc.

Isso porque essa atividade, por ter sido “[...] conservada como devaneio, abandona a dependência de objetos reais" (Freud, 1911, p. 240) ou a necessidade de subordinação a eles, pelo menos em alguns casos. Mas e quanto às consequências psíquicas dessa função preservada? Fazer arte, sonhar, qualquer coisa como o retorno a 
um período em que vivíamos longe da realidade, um pouco mais próximos do escoamento de tensões e da quietude.

Neste segundo tópico, tratarei da submissão do funcionamento psíquico ao "mecanismo do prazer". Algo sobre o qual Freud já tinha dado os primeiros passos no Projeto, atribuindo ao aparelho psíquico uma tarefa para além da de evitar a realidade. De um ponto de vista bem distante do homeostático de Fechner, admitiu que o sistema nervoso, enquanto suporte material do psiquismo, estaria conformado segundo uma arquitetura que afasta e, em situações ideais, escoa totalmente os estímulos recebidos.

Tese concebida com base no pressuposto científico moderno de uma lei geral do movimento, a qual diferencia atividade e repouso segundo uma abordagem quantitativa e qualitativa. Essa lei acompanhou suas considerações acerca de alguns fenômenos, dentre eles, o da consciência.

O fato que nos interessa particularmente é que distinto da lei da inércia, Freud concebeu um Princípio de inércia nervosa. Segundo ele, "[...] o neurônio aspira a libertar-se de $\mathrm{Q}^{8}$. Cabe compreender-se a partir dele arquitetura e desenvolvimento, assim como desempenhos" (Freud, 1895, p. 10). Trata-se de um sistema nervoso que executa a função de manter a variação de estímulos em seu interior igual ou próxima de zero. O sucesso dessa função ocorre quando a porção sensorial, impactada por estímulos externos, toma providências motoras que prontamente os escoam.

Para o bom entendimento desse ponto de vista, julgo importante compartilhar o esclarecimento de Gabbi Junior (1995/2003) quanto ao fato de que a lei da inércia não regula uma tendência ao repouso. Por sua vez, distinto dela, o Princípio da inércia, como concebido por Freud, além de expressar a ausência de acelerações, expressa também a ausência de movimento. Assim, como disse, ele "[...] exprime um caso em que a partícula material mantém o seu estado de movimento, cujo estado é o repouso" (Gabbi Junior, 2003, nota 7, p. 27) ou, como havia dito em edição anterior da mesma obra, "o princípio da inércia exprime um caso particular da lei da inércia, aquele onde a diferença entre movimento e repouso é nula" (Gabbi Junior, 1995, nota 7, p. 112). Continuou, “[...] o princípio da inércia expressa a tendência do sistema nervoso de

\footnotetext{
${ }^{8}$ Símbolo que no Projeto representa carga elétrica. 
evitar que ajam sobre ele forças que o obrigariam a abandonar seu estado de repouso" (Gabbi Junior, 2003, nota 10, p. 28). Antes de tirarmos conclusões, é importante registrar que Gabbi Junior recusou a tese de que o Projeto já supunha, ainda que embrionariamente, a noção de instinto de morte, porque a morte foi concebida nessa obra como algo externo à vida "[...] e não como algo interno e condutor da vida, como será em 1920" (Gabbi Junior, 2003, nota 26, p. 34).

O fato é que a abordagem quantitativa dessa obra sustenta que, de início, o sistema nervoso consistia apenas do conjunto de neurônios aos quais Freud nomeou phi, numa extensão que vai da extremidade perceptiva à motora do sistema. Apresentou, assim, a hipótese de um sistema nervoso primitivo que exerce funções sensoriais e motoras por meio do movimento arco-reflexo. Este seria orientado pelo Princípio de inércia, o qual atuaria em uma combinação necessária e suficiente para manter o sistema nervoso livre de estímulos.

Como sabemos, a alteração dessa função foi provocada já a partir do interior do organismo. Disse Freud (1985, p. 10), “[...] o sistema nervoso recebe estímulos do próprio elemento corporal, estímulos endógenos, que devem ser igualmente eliminados", mas cuja execução não se dá completamente, por causa de sua emissão constante. Originários das células corporais por ocasião da fome, respiração e sexualidade, operam de modo a não possibilitar total escoamento, pois exercem pressão continuamente. Dessa forma, o sistema nervoso passa a promover o armazenamento de parte desses estímulos, inclusive utilizando-os como combustível para seu funcionamento, de modo a promover alterações na realidade. Um funcionamento pelo tempo de aquiesce-los, de administrá-los. Um procedimento adaptativo? Talvez não se trate de alterações que visem cumprir mais tarde a finalidade que o aparelho se viu impedido de realizar de imediato.

Mas o fato é que devemos à atuação dos estímulos endógenos a instauração do segundo princípio, o de constância que orienta um tipo de oposição à inércia, justificado pelas exigências da vida. Sendo assim, a partir desse momento, a atuação do Princípio do prazer perderia seu caráter inercial, passando a orientar menos o escoamento total da excitação do que seu excesso, de modo a impedir que qualquer acréscimo de estímulo danifique o sistema, mantendo seu nível constante. Assim, como dito acima, ao lado da função primária, uma secundária tem início, implicando, além da manutenção de um nível adequado de excitação, um constante recarregamento do sistema. Não há dúvida 
de que, pelo menos aparentemente, estamos diante de um funcionamento homeostático do aparelho. A prevalecer esse ponto de vista, Freud pouco se distinguiria de seus mestres.

De fato, o recurso ao ponto de vista quantitativo apresenta limites e por isso Freud também atentou para o qualitativo em questões como a constituição das funções psíquicas, as motivações das nossas ações, o passarmos da indiferença à atenção e do repouso ao movimento. Certamente, para dar conta dessa demanda teórica, Freud introduziu no Projeto um tópico dedicado à dor e dele extraiu consequências. Introduziu-a como um acometimento inconveniente e falho no funcionamento do sistema nervoso, uma invasão por grandes quantidades de excitação não evitadas desde os órgãos sensoriais. Assim, a partir dessa situação, foi possível pensar o desprazer e a dor como fatores que põem tanto phi (percepção-consciência) como psi (memória) em movimento, posto que estimulam o sistema ao cumprimento de sua nova função. Mas é preciso distingui-las, pois, no Projeto, enquanto o desprazer foi relacionado à simples presença de estímulos, a dor foi "[...] caracterizada como irrupção de Qs enormes em phi e psi, ou seja, de Qs de uma grandeza ainda maior do que os estímulos phi" (Freud, 1895, p. 21).

Freud avançou tratando, em tópico também específico, do problema da qualidade, que inclusive envolveu um segundo fator, o da consciência. Um tema espinhoso para seu enfoque científico-naturalista. Admitiu que o problema todo se resumia na necessidade de "[...] incorporar o conteúdo da consciência em nossos processos Psi quantitativos. A consciência dá-nos o que se chama qualidades, sensações [...]" (Freud, 1895, p. 22).

Para dar conta dessa questão, postulou a existência de um terceiro conjunto de neurônios ao qual chamou Ômega, em “[...] cujos estados de excitação dariam como resultado as diferentes qualidades, ou seja, seriam as sensações conscientes" (Freud, 1895, p. 23). Argumento sustentado no reconhecimento de que ainda que uma ciência natural privilegie quantidades, cabe "[...] esperar da arquitetura do sistema nervoso que ele consista de dispositivos para transformar as quantidades externas em qualidades" (1895, p. 23). Uma vez organizado, me parece que a própria "tradução" das quantidades em qualidades que esse terceiro sistema opera oportuniza, com mais eficiência, à função primária do sistema, escoar os estímulos e o desprazer que os acompanha, só que conferindo-lhes qualidades, tornando-os conscientes. 
Impossível não ver no estatuto concedido à razão, digo, à consciência, um forte resquício da regência do Princípio do prazer em sua modalidade inercial. À maneira schopenhaueriana, Freud considerou a racionalidade humana como uma força derivada da vida instintiva, como um instrumento dela e de seus interesses e a eles associada. Nesses termos, endossou a hipótese de que os caminhos da civilização seriam indicados pelas forças instintuais, segundo sua motivação fundamental, o que possibilitou justificar fatos como a guerra, reconhecendo nela razões para satisfazer motivações as quais nada mais seriam que o cumprimento de interesses primitivos das forças instintuais. De sorte a admitir que a civilização emerge não para se opor ou constituir alternativa ao destino entrópico de cada um de seus membros, mas para finalizar o processo de evolução (conservadora) da vida rumo ao inorgânico.

Voltemos à sua abordagem naturalista para o problema da consciência. Freud considerou, além da intensidade, uma característica temporal dos estímulos, sua periodicidade, seu ritmo. Sustentou que o fundamento da consciência estaria a ela relacionado e que o sistema Ômega seria afetado segundo períodos de excitação, subsidiando a qualificação operada pela consciência, a qual apresenta, como um de seus conteúdos, a série de sensações de prazer e de desprazer. Dessa forma, prazer (do escoamento) e desprazer (de sua presença) estariam sempre referidos à ocupação do sistema, às sensações resultantes desta ocupação segundo intensidade e intermitência.

A consideração de que toda estimulação provoca desprazer e, por isso, suscita primeiro sua descarga total para, mais tarde, desencadear sua tolerância estratégica, apresenta, se não estou enganado, um diferencial em relação à época de Freud. Ele atribuiu à estimulação sensorial o ser em si mesma desprazerosa, posto que o prazer decorre de sua ausência. Retirou-lhe todo e qualquer conteúdo positivo, conduzindo às últimas consequências a concepção negativa do prazer ${ }^{9}$.

Tal negatividade do prazer aparece igualmente expressa em sua segunda teoria dos instintos e merece ser aqui brevemente mencionada, já que anuncia uma espécie de meta (para não dizer teleologia) da natureza que tudo conduz do inorgânico ao inorgânico, perspectiva que foi apresentada com todas as letras em 1920 na obra Além do princípio do prazer.

\footnotetext{
${ }^{9}$ Sobre esse argumento, consultar meu artigo "Prazer, Psicanálise!", Revista Natureza Humana, v. 11, 2009, além de "Desejo e prazer na idade moderna", de Luiz Roberto Monzani, Editora Champagnat, 2011.
} 
Nessa obra, ecoando o Projeto, Freud atribuiu aos instintos uma espécie de tendência de retorno à sua condição original de repouso e quietude. Sendo este o sentido da vida, ela nada teria de autossustentável e expressaria a nítida perspectiva entrópica que subsidiou seu pensamento. A importância dessa obra justifica a apresentação breve de algumas de suas teses.

Freud atribuiu uma característica universal aos instintos. Segundo ele,

um instinto é um impulso inerente à vida orgânica, a restaurar um estado anterior de coisas, impulso que a entidade viva foi obrigada a abandonar sob a pressão de forças perturbadoras externas, ou seja, é uma espécie de elasticidade orgânica, ou, para dizê-lo de outro modo, a expressão da inércia inerente à vida orgânica (Freud, 1920, p. 47).

Não parece haver dúvida de que retomou pressupostos de 1895; uma continuidade entre o movimento arco-reflexo daquele ano e a meta do instinto de 1920. Um pressuposto que manifesta uma concepção própria de instinto, uma concepção estranha ao que vemos em Lamarck, mas especialmente em Darwin (“A origem das espécies", de 1856), acerca do instinto caracterizado como portador e transmissor de algo adquirido. Nesses termos, a vida aparece como uma perturbação que não se consolida como aquisição permanente e transmissível.

Pelo caráter inercial da primeira obra e pelo caráter conservador da segunda, ficou evidente que Freud recusou a noção de conservação e homeostase, afastando-se de seus mestres. Isso porque, mesmo nos destinos alternativos dos instintos, suas vicissitudes, buscam um estado pretérito que toda substância viva se afastou e que procura retornar. Estranho a toda forma de vitalismo, parece claramente indicar que "a vida quer morrer". Argumento justificado ao mostrar que a vida só pode ter decorrido de uma evocação na matéria inanimada, uma "agressão" que ensejou um contra esforço por neutralizá-la. Sobre isso, Freud disse que foi assim que "[...] surgiu o primeiro instinto: o instinto a retornar ao estado inanimado" (1920, p. 49). Esse estado não consiste em uma consequência de um estímulo, mas de sua reação.

O retorno ao estado inorgânico pode ser identificado em máximas como a de que "tudo o que vive morre por razões internas" (Freud, 1920, p. 49), tese retomada em "O mal-estar na civilização", de 1929. O tornar-se mais uma vez inorgânico se daria por sua vinculação com a morte interna. Para Freud, com certeza (lembro aqui Gabbi Junior), 
pelo menos a partir de 1920, a morte não parece ser uma fatalidade externa, nem uma aquisição tardia da vida, como pensava Weismann.

Assim, o caráter involutivo que Freud concedeu à natureza, assim como à civilização, merece atenção, principalmente por sua cumplicidade com o caráter conservador do instinto. Juntos, evidenciam o primado e a resiliência do Princípio do prazer e de sua relação com o instinto de morte. Como nos ensinou Monzani (2014, p. 198), ele permite refletir sobre o estatuto do prazer na obra de Freud. Estatuto que Monzani declara que pode ser bem reconhecido, desde que nos desembaracemos de sua concepção positiva, possibilitando reconhecer que está, de fato, a serviço da regulação inercial, em verdade, da morte.

É importante lembrar que a força instintual orientada pelo Princípio do prazer, mesmo quando se manifesta pela repetição (Freud, 1920), também o faz para restabelecer um estado originário. Portanto, não se trataria de um simples fenômeno de repetição aberta e sem finalidade, muito menos um simples repetir monótono. É lícito dizer que a repetição restabelece um estado original, um estado "[...] já dado de antemão e que serve como finalidade (interna) da atividade repetitiva" (Monzani, 2014, p. 179). Trata-se de mais um ponto de vista que ecoa a tese de Schopenhauer, em "O mundo como vontade e como representação", acerca do privilégio do primeiro ocupante.

Concebida inicialmente com base na experiência clínica, a repetição decorre do fato de que uma representação emerge no psíquico como representante de uma força instintiva livre, não ligada, que, por isso, pressiona no sentido da descarga, o que pode ocorrer por meio de um objeto que lhe sirva de alvo. Para atender a essa meta, na impossibilidade de uma maneira direta, é necessária a mobilização do psiquismo para bloqueá-la, fixá-la, ligá-la. Trata-se do trabalho de ligação. É verdade que juntos, repetição e ligação parecem, à primeira vista, contradizer o Princípio do prazer, já que vinculam excitações livres em vez de escoá-las imediatamente. Dessa forma, é legítimo perguntar, como fez Freud (1920), se a repetição não seria mais primitiva e independente do Princípio do prazer.

Ele próprio nos ensinou que a repetição e a ligação de excitações proporcionam, na verdade, um ato preparatório, um ato preliminar, criador de condições para seu escoamento, portanto ainda submetido ao Princípio do prazer. Pensadas dessa maneira, repetição e ligação visam à descarga de excitações, enquanto propósito original. Mesmo quando causa desprazer ao Eu, a repetição e a ligação “[...] não contradiz[em] o 
princípio de prazer: desprazer para um dos sistemas e, simultaneamente, satisfação para outro" (Freud, 1920, p. 31). Tal argumento, em síntese, define o modo de funcionamento fundamental da força instintiva e o modo de funcionamento sequente do aparelho psíquico, isto é, através da repetição e da ligação como estratégia para retornar a um estado originário.

Trata-se de uma tendência que Freud, especulativamente, considerou como um atributo da vida orgânica em geral, uma verdadeira expressão da inércia dos organismos que visa ao estado inorgânico mineral, perturbado em algum momento ainda insuficientemente conhecido. Extrapolando essa noção, pode-se dizer que toda ordem biológica e cultural estaria sujeita ao mesmo movimento.

Nunca é demais reconhecer que o Princípio do prazer, se tomado como o orientador do escoamento do excesso (ou acúmulo) de excitação, funcionaria de fato como princípio regulador e conservador dos processos psíquicos à maneira anunciada por Freud no capítulo VII de "A interpretação dos sonhos", de 1900. Caso em que foi identificado com o Princípio de constância, o qual expressaria a tendência do aparelho psíquico de se conservar homeostaticamente. Nesse caso, devo reconhecer mais uma vez que estaríamos diante de uma perspectiva positiva do prazer. Mas as coisas nem sempre se passaram assim.

Como vimos, no primeiro capítulo de "Além do princípio", já bem longe da influência de Breuer e outros, a noção de prazer e de seu princípio ordenador ganhou novo estatuto para Freud. Nessa obra, o conceito perdeu qualquer função de guardião da saúde psíquica, isto é, de responsável pela sustentação de um nível constante de tensão. Ao contrário, ganhou a função de serviçal das primitivas forças instintivas, sobretudo as de morte. Seria correto dizer que Freud, nessa ocasião, teria assumido uma posição contraditória? Penso que não.

E a resposta é não se considerarmos que, em 1920, o Princípio do prazer apenas recuperou, como vimos, o estatuto apresentado no "Projeto", ou seja, o de manter o aparelho livre de excitações. O que ocorreu é que, em 1920, Freud retirou o Princípio do prazer da subordinação ao Princípio de constância. Como disse Monzani (2014, p. 191), nesse momento, Freud de fato expôs o caráter paradoxal do prazer, pois trouxe a questão de saber se ele seria guarda costas da vida ou lacaio da morte. Evidentemente, não se trata de uma questão simples, uma vez que tanto a função de promover a ausência total de excitação quanto a sua manutenção em nível constante estiveram 
presentes na obra de Freud.

Contudo, é verdade que em 1924 Freud retomou o ponto de vista de 1900, de "A interpretação dos sonhos". Foi em "O problema econômico do masoquismo", em função de um fato que, com toda cautela, arrisco compreender, inspirado em Kuhn, como uma quebra das expetativas paradigmáticas em razão do difícil problema clínico do masoquismo. $\mathrm{O}$ masoquista associa prazer com sofrimento e nele pretende permanecer. Nesse caso, Freud, no que pareceu uma reconstrução de sua teoria (não um simples retorno ao passado), dissociou (novamente) o Princípio do prazer da tendência inercial, identificando-o à constância, o que expôs ainda mais o caráter nuançado de suas construções teóricas ${ }^{10}$.

Segundo Kuhn, talvez possa se trata de um procedimento que visa ajustar a teoria do paradigma, assim, o fenômeno do masoquismo poderia ser entendido como uma anomalia encontrada, uma novidade fatual que exigiu uma novidade teórica, "de tal forma que o anômalo se tenha convertido no esperado" (Kuhn, 1998, p. 78). O resultado disso seria, se não outro paradigma, pelo menos um ajuste dos domínios do que podemos chamar sua ciência normal, uma atitude que talvez tivesse provocado uma quebra de paradigma, não fosse pelos desdobramentos conhecidos. Com isso quero dizer que sabemos que Freud produziu uma reinterpretação dos dados à luz da teoria anterior, restabelecendo a finalidade mortuária que perpassa sua obra.

$\mathrm{Na}$ verdade, Freud nunca renunciou à tese de que todo organismo vivo e toda civilização atingiriam, por caminhos próprios, sua meta de morte. Dessa forma, todos se equilibrariam precariamente entre os guardiões da vida e os lacaios da morte, o que explicita uma notável e invulgar teleologia entrópica a nortear a ordem biológica e a civilização. Assim, mesmo o estímulo à ordem biológica ou à organização da vida social não evitariam a finalidade entrópica, mas a estimulariam pela crescente produção de neurose e de mal-estar. Já se argumentou que a complexificação de todo organismo vivo, de todo homem e toda civilização possibilitariam a superação da pretérita

\footnotetext{
${ }^{10}$ A questão do masoquismo enfrentada na clínica talvez não tenha alcançado a condição de anomalia nem de uma crise de sua ciência normal que exigisse um novo paradigma. Nesse caso, sua atitude poderia ser compreendida pelo argumento de Kuhn (1998, p. 107) de que os cientistas "[...] não renunciam ao paradigma que os conduziu à crise [...] não tratam as anomalias como contra-exemplos [...]”. Seria o caso em que uma resistência teria ocorrido, uma vez que, como continuou Kuhn mais adiante, "“...] a fonte dessa resistência é a certeza de que o paradigma antigo acabará resolvendo todos os seus problemas e que a natureza pode ser enquadrada na estrutura proporcionada pelo modelo paradigmático" (Kuhn, 1998, p. 192).
} 
condição inerme e de ensimesmamento e que também possibilitariam o escoamento de desordem, escapando à entropia do mundo físico e inorgânico. Mas não parece ser esse o ponto de vista de Freud.

Desse modo, parece evidente que resta a Eros, por seus próprios e diferentes caminhos, não contradizer nem destronar Tânatus, mas conduzir a vida de modo que o viver não seja mais do que assumir o encargo de construir uma civilização atendendo à máxima do Princípio do prazer, o qual, segundo Freud, “[...] parece, na realidade, servir aos instintos de morte" (Freud, 1920, p. 74). Trata-se de um princípio que orienta imperativamente a tendência à emancipação das excitações, à condução de toda forma de vida ao gélido repouso do inanimado, condução traçada filogeneticamente na ocasião do "milagre" da emergência da vida. Como já dizia Seifert (1753), que poderia ter inspirado Freud, consequência do toque dos raios solares sobre a matéria inanimada.

Nesse cenário, os instintos conservadores da vida, identificados por Freud como do Eu, foram para muitos a ilusão de que a luta contra a morte poderia obter êxito, que poderia conduzir o ser vivo a uma condição evoluída, a um progresso sustentável, alcançando um desenvolvimento superior pela via de ligações crescentes e constantes. Por essas e por outras razões, Freud rechaçou a hipótese de que exista em ação no homem um instinto para a perfeição responsável por um elevado estágio de desenvolvimento orgânico ou de realização intelectual e moral. O autor declarou taxativamente "[...] não tenho fé, na existência de tal instinto interno e não posso entender porque essa ilusão benévola deva ser conservada" (Freud, 1920, p. 52). Tal ilusão, no sentido de maior perfeição, seria resultado da própria repressão instintual que alicerça a civilização e o engana sobre os destinos da vida na Terra.

$* * * * *$

Com isso, espero ter minimamente oferecido argumentos para compreender a psicanálise de Freud como um modelo ou ainda um dispositivo autóctone, como disse Lebrun (1977, p. 15), concedendo-lhe "o estatuto de um texto" que se pode examinar como um corpus de formulações, enunciados, protocolos, direções de investigação e do qual "[...] cada articulação expressa uma escolha ou uma decisão” (Lebrun, 1977, p. 15); mas também como um paradigma incomensurável, na verdade, dotado de incompatibilidade com seus antecedentes e pósteros por “[...] suas maneiras de ver o 
mundo e nele praticar a ciência" (Kuhn, 1998, p. 23). Por fim, reitero minha cumplicidade com Assoun, para quem a psicanálise é "[...] o produto da emergência de um tipo novo e específico de saber resultante de um processo determinado de que Freud é o lugar e o agente" (1983, p. 114), ponto de vista que acredito ser compartilhado por Loparic.

\section{Referências}

Assoun, P.L. [1978]. Freud. A filosofia e os filósofos. Rio de Janeiro: Ed. Francisco Alves, 1978.

Assoun, P.L. [1983]. Introdução à epistemologia freudiana. Rio de Janeiro: Ed. Imago, 1983.

Bocca, F.V. [2016]. Contribuição para o debate acerca de "uso compartilhado" em psicanálise. Psicanálise em perspectiva VI, Curitiba, 2016.

Bocca, F.V. [2017]. Freud e o programa científico kantiano. Revista Natureza Humana, 18(2), 2017.

Bocca, F.V.; Mouammar, C.C.E. [2011]. Civilização, sexualidade e entropia no pensamento de Freud. Revista Aurora, Curitiba, 23(33), 2011.

Freud, S. [1995/1885]. Projeto de uma psicologia. Trad. Osmyr F. G. Jr. Rio de Janeiro: Imago, 1995/1885.

Freud, S. [1969/1911]. Formulações sobre os dois princípios. Rio de Janeiro: Imago, v. XII, 1969/1911.

Freud, S. [1969/1915]. Os instintos e suas vicissitudes. Rio de Janeiro: Imago, v. XIV, $1969 / 1915$.

Freud, S. [1969/1920]. Além do princípio do prazer. Rio de Janeiro: Imago, v. XVIII, $1969 / 1920$.

Freud, S. [1969/1929]. O mal-estar na civilização. Rio de Janeiro: Imago, v. XXI, $1969 / 1929$.

Fulgencio, L. [2007]. Paradigmas na história da psicanálise. Revista Natureza Humana, 9(1), 2007.

Gabbi Junior, O.F. [1995]. Projeto de uma psicologia. Rio de Janeiro: Imago, 1995.

Gabbi Junior, O.F. [2003]. Notas a Projeto de uma psicologia. Rio de Janeiro: Imago, 2003. 
Kuhn, T. [1962]. A estrutura das revoluções científicas. São Paulo: Perspectiva, 1998.

Lebrun, G. [1977]. L'idée d'épistémologie. Revista Manuscrito, 1, 1977.

Monzani, L.R. [2014]. Freud: o movimento de um pensamento. Campinas:

EDUNICAMP, 2014.

Porchat, P. [2005]. Freud e o teste de realidade. São Paulo: Ed. Casa do psicólogo, 2005.

Seifert, L.C. [1753]. Traité des trois imposteurs. Paris: BNF Gallica, 1953. 